\title{
DISODIUM ETIDRONATE IN THE PREVENTION OF HETEROTOPIC OSSIFICATION FOLLOWING SPINAL CORD INJURY (PRELIMINARY REPORT)
}

\author{
By Samuel L. Stover, M.D., Harry R. Hahn, M.D. and John M. Miller, III, M.D. \\ Spain Rehabilitation Center-University of Alabama in Birmingham, Alabama \\ Craig Hospital, Englewood, Colorado
}

\section{Introduction}

Heterotopic ossification is a frequent complication of acute severe neurological conditions. An incidence of $\mathrm{I} 6$ per cent to 53 per cent has been reported following spinal cord injury (Venier \& Ditunno, I97I). It occurs most frequently I to 4 months after injury below the level of paralysis and forms adjacent or more distant to the major joints. Prospective surveys have shown that the hips are most frequently involved followed by knees, shoulders, elbows and spine (Stover et al., 1975). The extent of ossification may be minimal and identified only as coincidental X-ray findings. With more extensive involvement, ossification may cause severe limitation of motion due to ankylosis in about 3 per cent of spinal cord injury patients (Wharton \& Morgan, I970). Restricted joint motion may cause further functional impairment and skin breakdown, limiting rehabilitation goals.

The onset of larger masses of heterotopic ossification is often characteristic of any inflammatory reaction. Rather suddenly a warm and swollen extremity becomes obvious clinically. Fever may or may not occur. The swelling is often more localised than that found with thrombophlebitis and, within several days, a more circumscribed, firmer mass is palpable within the area of oedema. If the mass is adjacent to a joint, a gradual loss of passive range of motion may follow. An elevated serum alkaline phosphatase may be of value in differentiating early heterotopic ossification from other clinical entities (Nicholas, 1973); however, radioisotope bone scans may be the only early definitive method of diagnosis (Rossier, I975). Routine X-rays may not show evidence of early calcification for 7 to ro days after the clinical signs appeared.

The inflammatory-type reaction causes connective tissue oedema and cell metaplasia with immature-appearing connective tissue, chondrogenesis, and osteogenesis (Rossier et al., I973). Mineralisation of the tissue involves an amorphous calcium phosphate phase, which is gradually replaced by enlarging hydroxyapatite crystals. This leads to the formation of lamellar cortico-spongiosal bone with a thin cortex, tightly latticed spongiosa, and only occasional Haversian systems. These features are characteristic of non-tumoural new bone formation such as fracture callus and distinguish it from normal bone (Rossier et al., 1973).

The aetiology and pathogenesis of heterotopic ossification are still unknown. Prevention has been impossible. Disodium etidronate is the first therapeutic agent to show any effectiveness in inhibiting the formation of heterotopic ossification. 


\section{Materials}

The diphosphonates are simple chemical compounds characterised by phosphorus-carbon-phosphorus bonds. They possess properties similar to the naturally occurring inorganic pyrophosphate, which is hypothesised to be a regulator of biological calcification, but have the advantage of being absorbed intact from the gut. Unlike inorganic pyrophosphate, the diphosphonates are almost totally stable to chemical and enzymatic degradation.

One of the diphosphonates, disodium etidronate (generic name of disodium ethane-l-hydroxy-1, 1-diphosphonate (EHDP)), is known to have profound effects on crystal behaviour in vitro and in experimentally induced soft tissue calcification. In vitro, EHDP blocks the transformation of amorphous calcium phosphate into crystalline hydroxyapatite without inhibiting the formation of the initial or nucleation phase (Francis et al., 1969). In addition, diphosphonates inhibit the precipitation of calcium phosphate from solution. EHDP probably alters crystallisation by the inhibition of heterogenous nucleation and subsequent growth and aggragation of hydroxyapatite crystals (Russell et al., 1973). In vivo, EHDP inhibits aortic and renal calcification in rats given large doses of vitamin $\mathrm{D}_{3}$ (Fleisch et al., 1970), calcium deposition in skin induced by dihydrotachysterol (Casey et al., 1972) and prevents periarticular calcification and articular changes associated with adjuvant arthritis in rats (Francis et al., 1972). EHDP may also have important direct or indirect effects on bone cells (Russell et al., I974). EHDP is not metabolised and is excreted in the urine unchanged. Bone is the only tissue where EHDP accumulates to any appreciable extent (Michael et al., 1972; Wellman et al., 1973).

Although the exact mechanism of action of EHDP is still unknown, the invitro and experimental animal model data suggested the diphosphonates may be effective in preventing heterotopic ossification following spinal cord injury. This prospective clinical double-blind study was undertaken to test this hypothesis.

\section{Methods}

One hundred and sixty-six spinal cord injury patients were included in a double-blind study at Spain Rehabilitation Center in Birmingham, Alabama, and Craig Hospital in Englewood, Colorado, between 1972 and 1975. All were male patients over I6 years of age. L2 was the lowest neurological level accepted into the study, and all patients had complete motor paralysis while a few had minimal sensory sparing. Patients were started on the clinical study 20 to I2I days after injury with a treatment period designed for $\mathrm{I} 2$ weeks. Patients who had severe acute or chronic disease which might interfere with interpretation of the results were excluded from the study. Patients who were receiving hormone therapy and who had received corticosteroids for longer than 2 weeks at the time of acute injury were also excluded. No steroids were allowed for at least 7 days prior to inclusion in the study. Routine prestudy examinations included the history and physical examination, complete blood counts, serum chemistries (SMA-I8), urine chemistries, renal clearance tests, electrocardiogram, X-rays of the chest and abdomen, plus anteroposterior (AP) and lateral X-ray views of both hips and knees.

EHDP was given in a dosage of approximately $20 \mathrm{mg} / \mathrm{kg} /$ day for the first 2 weeks, followed by $10 \mathrm{mg} / \mathrm{kg} /$ day for the remainder of the study. The drug and placebo were supplied as $200 \mathrm{mg}$ tablets and administered orally I hour before 


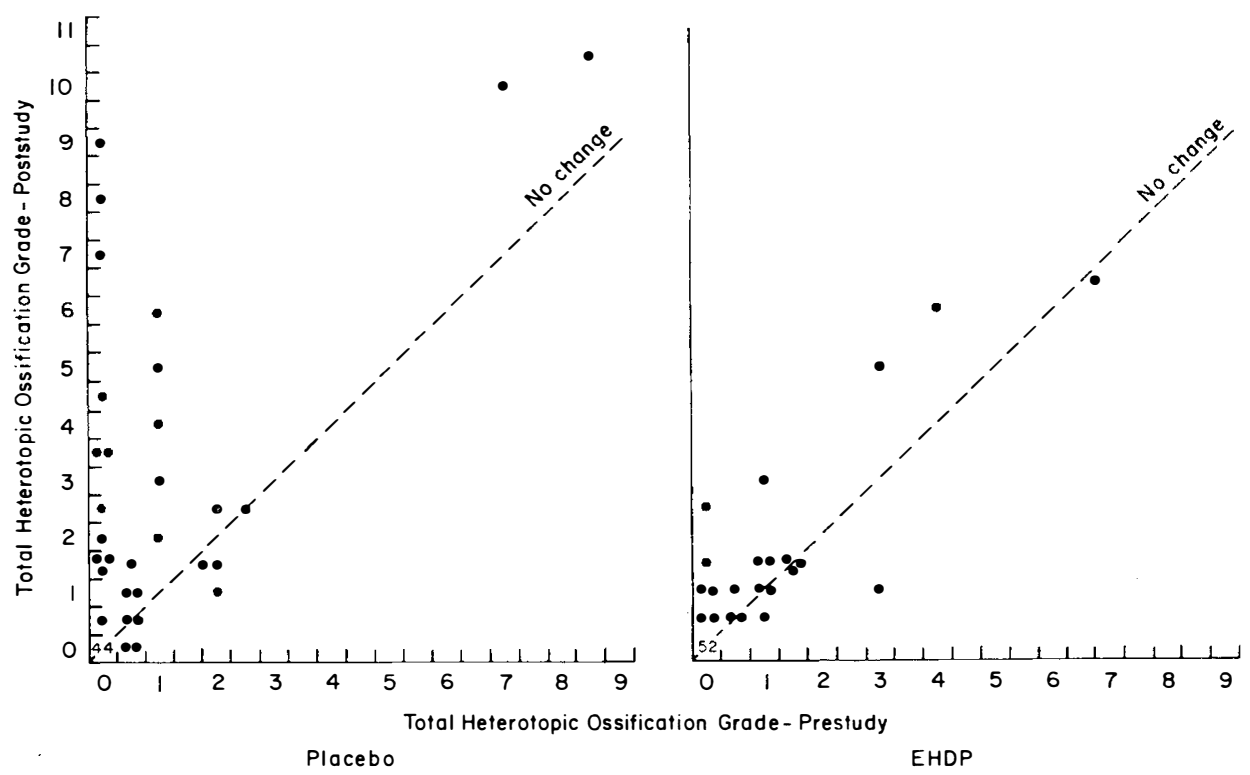

FIG. Ia

FIG. Ib

Change in total heterotopic ossification grade during 8 to 12 week study. Numbers in left lower cells represent patients with zero prestudy and poststudy grades. Each dot represents a patient who developed heterotopic ossification before or during the study.

Patients with increasing total heterotopic ossification grades during the 8 to 12 week study fall above the 'no change' line, while those with decreasing grades are below the line. In the placebo group fig. Ia, the increasing (positive) distribution of the total heterotopic ossification grade is more frequent and of greater magnitude compared to those in the EHDP group (fig. Ib).

breakfast with a glass of fruit juice. The patients were maintained on a routine diet and continued in their regular rehabilitation programme. Biweekly serum alkaline phosphatase determinations were made in addition to repeating the SMAI 8 during the eighth and twelfth weeks of the study. AP and lateral X-rays of the hips and knees were obtained every four weeks throughout the study. Side effects and unexpected clinical reactions were documented. Follow-up examinations were attempted at 3, 6, and 9 months following drug discontinuation.

Radiological evidence of heterotopic ossification was graded $0,0.5, \mathrm{I} \cdot 0, \mathrm{I} \cdot 5$, $2 \cdot 0, \ldots, 4^{\circ}$, with the $4^{\circ} 0$ grade being defined as the maximum amount of heterotopic ossification expected around the hips and knees and generally causing ankylosis. Since the hips and knees were evaluated bilaterally, a total score of I6 would be possible where maximal heterotopic ossification formed about all four joints examined. The protocol called for independent evaluation by each clinical centre of their own X-rays. To test this method of evaluation, approximately half of the $\mathrm{X}$-rays were reviewed by three independent examiners (a radiologist and two of the authors, S. L. S. and H. R. H.) and again on a joint evaluation. All evaluations were carried out on a 'blind' basis. These evaluations resulted in grades with differences of less than 0.5 grade between examiners; therefore, the X-ray grading system was determined acceptable for purposes of this report. Some variability in this type of subjective grading is expected and accounts for most of the minor decreases of total heterotopic ossification shown. 


\section{TABLE I}

Patients in study average \pm one standard error

$\begin{array}{lcc} & \text { Placebo } & \text { EHDP } \\ \text { Number patients entered in study } & 84 & 82 \\ \text { Number completing 8-I2 weeks treatment } & 75 & 74 \\ \text { Age } & 25 \pm 0 \cdot 9 & 28 \pm \mathrm{I} \cdot 3 \\ \text { Number of days after injury to study } & 56 \pm 2 \cdot 5 & 58 \pm 2 \cdot 6\end{array}$

TABLE II

Prevalence of heterotopic ossification prestudy and postudy*

$$
\begin{array}{lccc} 
& \text { Prestudy } & \text { Poststudy } & \begin{array}{c}
\text { Increase } \\
\text { During } \\
\text { Study }
\end{array} \\
\text { Placebo } & \text { I9 }(25 \%) & 3 \mathrm{I}(4 \mathrm{I} \%) & \text { I2 }(16 \%) \\
\text { EHDP } & \text { I6 }(22 \%) & 22(30 \%) & 6(8 \%) \\
\text { * Based on } & \text { I49 patients }(75 \text { placebo, } 74 \text { EHDP). }
\end{array}
$$

\section{Results}

One hundred and sixty-six patients entered the study with 149 patients (75 placebo, 74 EHDP) completing at least 8 and no more than 12 weeks of drug therapy. The data from I49 patients are analysed statistically and included in this report (Table I).

\section{Prevalence of Heterotopic Ossification}

At prestudy time (average 56 days in placebo and 58 days in EHDP patients 25 per cent of the placebo patients and 22 per cent of the EHDP patients already has X-ray evidence of heterotopic ossification about the hips and/or knees (Table II). During 8 to 12 weeks of the drug study, there was a I6 per cent increase in the prevalence of heterotopic ossification in the placebo group and an 8 per cent increase in the EHDP group; i.e. poststudy prevalences are $4 \mathrm{I}$ per cent and 30 per cent respectively.

\section{Changes in the Total Heterotopic Ossification during Study}

Plotting the prestudy total heterotopic ossification grade against the poststudy grade, there is a greater positive change in the placebo patients (fig. Ia) compared to EHDP patients (fig. Ib). Of 75 patients in the placebo group, 44 were negative for heterotopic ossification both prestudy and poststudy, I9 were positive prestudy, and 12 became positive for heterotopic ossification during the 8 to I2 week study. Of 74 patients in the EHDP group, 52 remained negative both prestudy and poststudy, I6 were positive prestudy, and six became positive for heterotopic ossification during the 8 to 12 week study.

In those patients who had no heterotopic ossification prestudy, the average total grade increase of heterotopic ossification was 0.78 in the placebo group compared to 0.12 in the EHDP group during the 8 to 12 week study. In patients who were positive for heterotopic ossification prestudy, there was a mean increase

$$
\text { I } 4 / 2-D
$$




\section{TABLE III}

Mean change in total heterotopic ossification grade from zero baseline during 8-I 2 week study

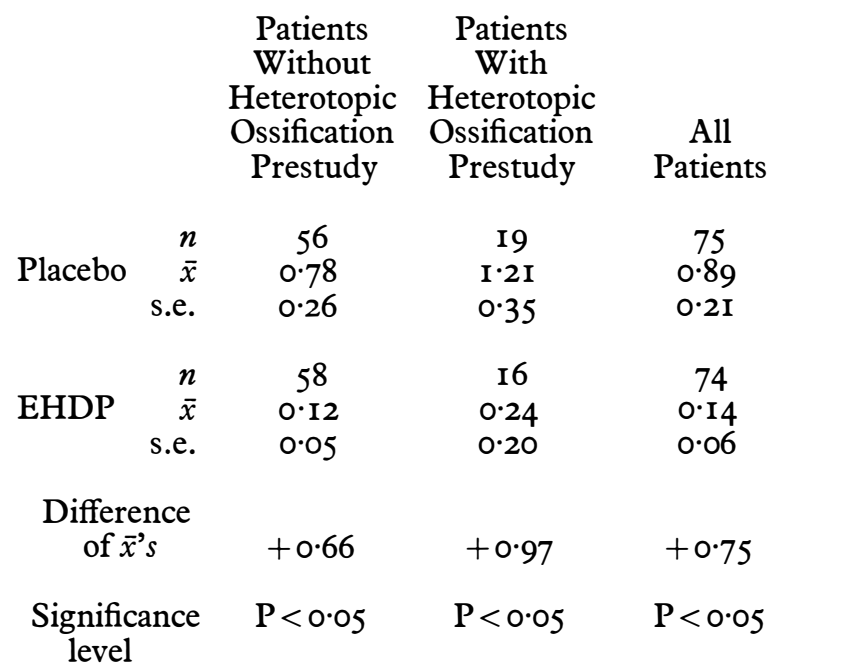

of $\mathrm{I} \cdot 2 \mathrm{I}$ in the placebo group and 0.24 in the EHDP group during the 8 to $\mathrm{I} 2$ week study (Table III). These figures show there is significantly less heterotopic ossification development $(\mathrm{P}<0.05)$ in the EHDP group compared to the placebo group in patients who develop any degree of heterotopic ossification during the study or who already had evidence of heterotopic ossification before EHDP therapy was started. This is also true in the total heterotopic ossification grade change in all patients of the two groups (Table III).

Fewer patients who were negative prestudy developed X-ray evidence of heterotopic ossification while on EHDP therapy (6) compared to placebo (I2) (fig. 2). The total grade increase is also much less. Reviewing the X-rays of those who developed an initial appearance of heterotopic ossification while on EHDP treatment, five of six patients became positive within the first 4 weeks of treatment with no progression after 4 weeks; whereas, only one patient became positive between the fourth and eighth week of treatment.

\section{Follow-up Data}

Of 38 consecutive patients who completed 8 to 12 weeks of the double-blind study at one of the centres, 32 returned for follow-up evaluation (9 to 12 months) after the study. Their X-ray findings were compared with the prestudy and poststudy X-rays. Of these 32 patients (placebo I4, EHDP I8), I8 patients (placebo 7, EHDP I I) developed heterotopic ossification from the time of injury to the time of follow-up. The total heterotopic ossification grade for these prestudy, poststudy, and follow-up X-rays are given in Table IV and figures $3 a$ and $b$. The mean increase of total heterotopic ossification during the double-blind study period for placebo group was +2.9 compared to +0.3 for the EHDP group. Yet, when EHDP treatment was terminated (poststudy to follow-up), there was less increase during that time period in the placebo group compared to the EHDP group, +0.9 and $+\mathrm{I} \cdot 4$ respectively. The mean total increase of heterotopic 

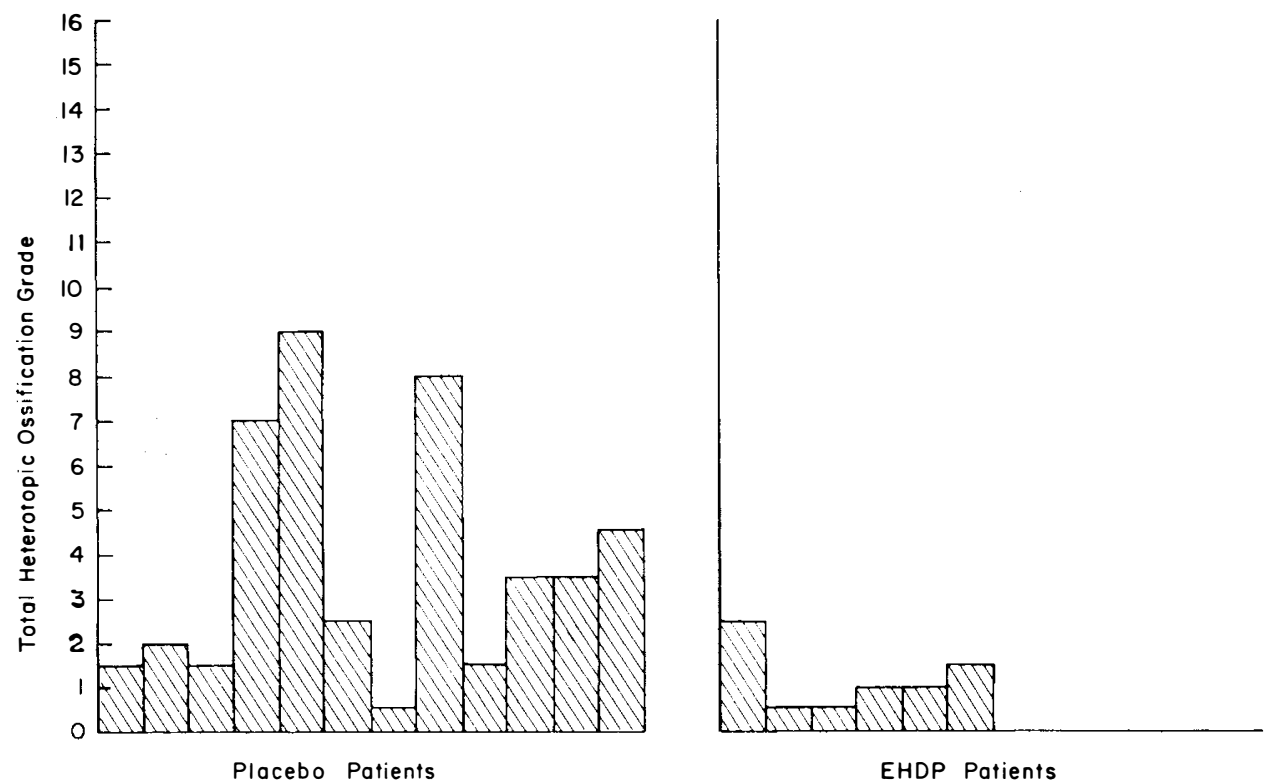

FIG. 2

Patients without prestudy X-ray evidence of heterotopic ossification who developed heterotopic ossification during the 8 to 12 week treatment period.

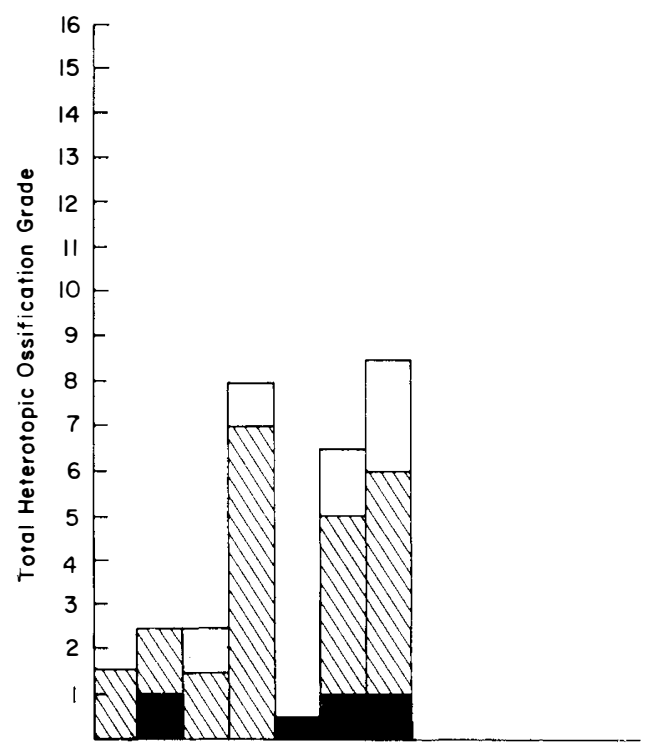

Placebo Patients

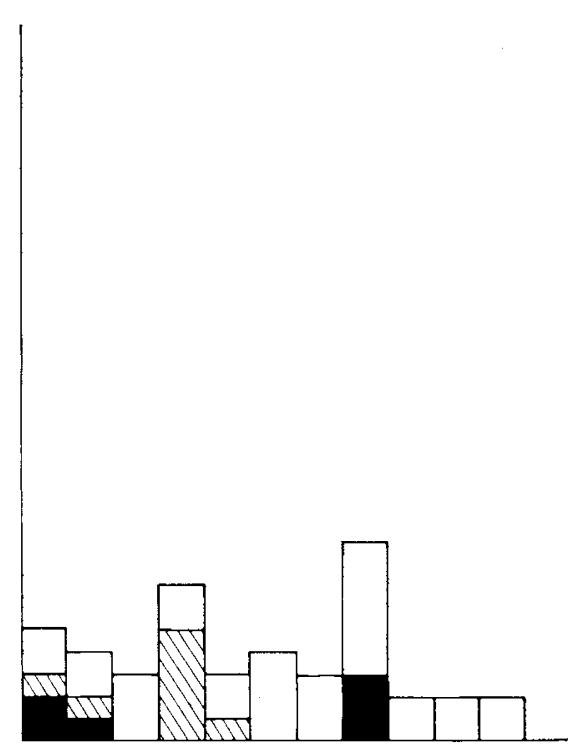

EHDP Patients

FIG. 3

- Total heterotopic ossification grade (X-ray evidence) prestudy.

Increase or new formation (total heterotopic ossification by $\mathrm{X}$-ray evidence) during 8 to 12 week treatment period.

$\square$ Increase or new formation (total heterotopic ossification by X-ray evidence) during 9 to 12 month follow-up period. 
ossification, however, was still higher in the placebo group, +3.8 compared to $+\mathrm{I} \cdot 8$ for the EHDP group. This is illustrated in Figures $3 a$ and $b$; it may be observed that the total heterotopic ossification grade increase during the 8 to 12 week treatment period is more in the placebo group compared to the EHDP group, but during the follow-up period, there is relatively more heterotopic ossification development in the EHDP patients. In the EHDP group, six patients who were negative on poststudy X-ray became positive during the follow-up period (fig. $3 \mathrm{~b}$ ). Most of these became positive during the first 3 months after EHDP withdrawal, and the total grade never became as great as in the placebo patients.

\section{Side Effects}

There was an expected elevation of serum phosphate in EHDP-treated patients (Recker et al., 1973), but this had no known clinical effects. The only clinical side effects noted were minor gastrointestinal symptoms, such as mild diarrhoea, nausea, vomiting, or abdominal distress. One or more of these symptoms occurred in 14.5 per cent of the placebo group compared to 16.9 per cent of the EHDP-treated group. Diarrhoea was noted in three placebo patients, nausea in six placebo and seven drug patients, vomiting in three placebo and four drug patients, and other abdominal distress in three drug patients. Two EHDP patients elected to discontinue the study due to their gastrointestinal symptoms. This similar distribution suggests that the gastrointestinal symptoms may be secondary to the bulk effect of the tablets (i.e. a $70 \mathrm{~kg}$ man required seven tablets at 20 $\mathrm{mg} / \mathrm{kg} /$ day administered in a single daily dose) or is coincidental and secondary to early spinal cord injury rather than to the effects of EHDP itself. Lack of other laboratory or clinically observed side effects in the parameters studied suggests that EHDP is safe for clinical use. The safety of EHDP is further documented in clinical trials of Paget's Disease (Altman et al., I973; Khairi et al., 1974; Russell et al., 1974).

\section{Discussion}

The data indicate EHDP does significantly prevent mineralisation of heterotopic ossification following spinal cord injury as identified by X-ray studies. The mean total grade of heterotopic ossification in EHDP-treated patients for 8 to $\mathrm{I} 2$ weeks is significantly less $(\mathrm{P}<0.05)$ compared to placebo-treated patients. Although fewer EHDP patients who were negative prestudy developed heterotopic ossification during the 8 to I2 weeks' double blind study, the overall prevalence may not be much different a year later. The follow-up numbers are admittedly small but suggest that the 8 to $\mathrm{I} 2$ week period of EHDP treatment has decreased the ultimate total amount of heterotopic ossification a patient may develop. Smaller total amounts indicate less extensive heterotopic ossification around any single joint. This makes it unlikely a patient will develop severe heterotopic ossification which would limit range of motion to such an extent that functional abilities are impaired.

There is also some evidence EHDP treatment started less than 60 days after injury is more effective than when it is started more than 60 days after the time of injury. This should be obvious since a prevalence of 25 per cent in the placebo and 22 per cent in the EHDP group was already noted on prestudy X-rays, when the average starting time of treatment was 56 and 58 days after injury respectively Since the clinical and X-ray appearance of heterotopic ossification is most common I to 4 months after injury (Stover et al., I975), but occurs as early as I9 days 


\section{TABLE IV}

Study and follow-up data on 18 patients who developed heterotopic ossification from total of 32 of 38 consecutive patients ${ }^{\star}$ who were available for all studies

Placebo

Total heteropic ossification grade

\begin{tabular}{|c|c|c|c|c|c|}
\hline Patient & Prestudy & Poststudy & $\begin{array}{l}\text { Follow-up } \\
(9-\mathrm{I} 2 \mathrm{mo})\end{array}$ & $\begin{array}{c}\text { Poststudy } \\
\text { to } \\
\text { follow-up } \\
\text { increase }\end{array}$ & $\begin{array}{l}\text { Prestudy } \\
\text { to } \\
\text { follow-up } \\
\text { increase }\end{array}$ \\
\hline I & 0 & $I \cdot 5$ & $\mathrm{I} \cdot 5$ & 0 & $+I \cdot 5$ \\
\hline 2 & $I \cdot O$ & $2 \cdot 5$ & $2 \cdot 5$ & 0 & $+I \cdot 5$ \\
\hline 3 & 0 & $I \cdot 5$ & $2 \cdot 5$ & $+\mathrm{I} \cdot 0$ & +2.5 \\
\hline 4 & 0 & $7 \cdot 0$ & $8 \cdot 0$ & $+\mathrm{I} \cdot \mathrm{O}$ & $+8 \cdot 0$ \\
\hline 5 & 0.5 & 0.5 & 0.5 & 0 & 0 \\
\hline 6 & $I \cdot O$ & $5 \cdot 0$ & $6 \cdot 5$ & $+\mathrm{I} \cdot 5$ & +5.5 \\
\hline 7 & $I \cdot O$ & $6 \cdot 0$ & $8 \cdot 5$ & $+2 \cdot 5$ & $+7 \cdot 5$ \\
\hline Mean & 0.5 & $3 \cdot 4$ & $4 \cdot 3$ & +0.9 & $+3 \cdot 8$ \\
\hline
\end{tabular}

EHDP

Total heterotopic ossification grade

\begin{tabular}{|c|c|c|c|c|c|}
\hline Patient & Prestudy & Poststudy & $\begin{array}{r}\text { Follow-up } \\
(9-12 \mathrm{mo})\end{array}$ & $\begin{array}{l}\text { Poststudy } \\
\text { to } \\
\text { follow-up } \\
\text { increase }\end{array}$ & $\begin{array}{c}\text { Prestudy } \\
\text { to } \\
\text { follow-up } \\
\text { increase }\end{array}$ \\
\hline I & $I \cdot O$ & $I \cdot 5$ & $2 \cdot 5$ & $+I \cdot 0$ & $+I \cdot 5$ \\
\hline 2 & 0.5 & $I \cdot O$ & $2 \cdot 0$ & $+I \cdot O$ & $+I \cdot 5$ \\
\hline 3 & 0 & 0 & $I \cdot 5$ & $+I \cdot 5$ & $+I \cdot 5$ \\
\hline 4 & 0 & $2 \cdot 5$ & 3.5 & $+I \cdot O$ & +3.5 \\
\hline 5 & 0 & 0.5 & $I \cdot 5$ & $+I \cdot O$ & $+I \cdot 5$ \\
\hline 6 & 0 & 0 & $2 \cdot 0$ & $+2 \cdot 0$ & $+2 \cdot 0$ \\
\hline 7 & 0 & 0 & $I \cdot 5$ & $+I \cdot 5$ & $+I \cdot 5$ \\
\hline 8 & I. 5 & $I \cdot 5$ & $4 \cdot 5$ & +3.5 & +3.5 \\
\hline 9 & 0 & 0 & $I \cdot O$ & $+I \cdot O$ & $+I \cdot 0$ \\
\hline IO & 0 & 0 & $I \cdot O$ & $+\mathrm{I} \cdot \mathrm{O}$ & $+I \cdot O$ \\
\hline I I & 0 & 0 & $I \cdot O$ & $+I \cdot O$ & $+I \cdot 0$ \\
\hline Mean & 0.3 & 0.6 & $2 \cdot 0$ & $+I \cdot 4$ & $+\mathrm{I} \cdot 8$ \\
\hline
\end{tabular}

* 38 consecutive patients in follow-up study (Placebo I9, EHDP I9)

32 patients returned for follow-up study (Placebo I 4, EHDP I8)

I8 patients developed heterotopic ossification from time of injury to follow-up study (Placebo 7, EHDP I I) 
after injury (Hardy \& Dickson, 1963), preventive treatment should be most effective if started within the first month after injury.

Several reasons can be suggested to explain the X-ray appearance of heterotopic ossification in at least five of the six patients who developed X-ray evidence of heterotopic ossification while on EHDP therapy.

I. X-rays were taken as a part of the total prestudy evaluation one to four days before EHDP treatment was started. During this time interval, heterotopic ossification formation may have been initiated.

2. X-ray evidence is often not apparent for 7 to to days after known clinical appearance.

3. It is hypothesised that therapeutic bone levels of EHDP may not be achieved for two or more weeks at a dosage of $20 \mathrm{mg} / \mathrm{kg} /$ day.

Any of these single factors or combination of factors may explain the X-ray appearance of heterotopic ossification during the first 4 weeks while on EHDP therapy without suggesting that EHDP failed to prevent mineralisation. It is of interest that vertebral fracture healing and other long bone healing did not appear to be inhibited or delayed as a result of EHDP treatment.

EHDP may also have an abortive effect on the pathogenesis of heterotopic ossification by inhibiting mineralisation. Several patients developed early clinical signs and symptoms of heterotopic ossification along with an elevated serum alkaline phosphatase during EHDP treatment; but, except for soft tissue swelling, $\mathrm{X}$-rays remained negative for the treatment period. Following EHDP withdrawal, these same patients developed X-ray evidence of heterotopic ossification. This suggests EHDP may not influence the origin of the matrix of heterotopic ossification but does appear to influence its ossification. The fact that this ossification does not become as extensive in the EHDP group compared to the placebo group (fig. 3) suggests the matrix continues to mature during the time mineralisation is inhibited by EHDP and that increased maturity of the matrix may have some influence on decreasing expected mineralisation.

This data is further supported by surgical studies of hip ankylosis secondary to heterotopic ossification in spinal cord injured patients, where EHDP prevented postoperative recurrence as long as it was given (Stover et al., 1975). There was no X-ray evidence of recurrent ossification while EHDP treatment continued for as long as 9 months. Termination of EHDP treatment allowed variable recurrence with some evidence that the extent of recurrence was inversely proportional to the length of EHDP therapy and the size of the initial bone mass.

These findings suggest EHDP can be effective in the prevention of heterotopic ossification if given before pathogenesis is initiated. EHDP has little known effect on heterotopic ossification, which has already formed, but may reduce the extensiveness of heterotopic ossification which is in the early process of formation. Further studies are necessary to determine the optimal time to institute EHDP treatment, length of treatment, and minimal effective doses of EHDP which can prevent heterotopic ossification after spinal cord injury. Since EHDP is the first known therapeutic agent in the prevention of heterotopic ossification, it may also prove useful in further studies to elucidate the aetiology and pathogenesis of the pathologic ossification.

\section{Conclusion}

In a double-blind, clinical study of I 49 spinal cord injury patients, disodium etidronate (EHDP) has proven its effectiveness in the prevention of heterotopic 
ossification. The extent of heterotopic ossification development as measured by the total heterotopic ossification X-ray grade was significantly less in EHDPtreated patients compared to placebo-treated patients $(P<0.05)$. For maximal effectiveness, EHDP treatment must be started before the onset of the pathological process initiating the development of heterotopic ossification. Further studies are necessary to determine the optimal time to institute EHDP treatment, length of treatment, and minimal effective dose, EHDP is the first therapeutic agent known to alter the formation of heterotopic ossification after spinal injury and may prove useful in other conditions where heterotopic ossification prevention is clinically indicated.

\section{SUMMARY}

Heterotopic ossification is a frequent complication following spinal cord injury with 16 per cent to 53 per cent of patients developing varying degrees of pathologic ossification.

The diphosphonates are known to block the transformation of amorphous calcium phosphate into crystalline hydroxyapatite. Therefore, one of the diphosphonates, disodium etidronate (generic name of disodium ethane-l-hydroxy-1, 1-diphosphonate (EHDP) was selected for clinical trials to study the effectiveness of EHDP in preventing heterotopic ossification following spinal cord injury.

In a double-blind, clinical study of I49 spinal cord injury patients, disodium etidronate has proven its effectiveness in the prevention of heterotopic ossification. The extent of heterotopic ossification development as measured by the total heterotopic ossification X-ray grade was significanlty less in EHDP-treated patients compared to placebo-treated patients $(P<0.05)$. For maximal effectiveness, EHDP treatment must be started before the onset of the pathological process initiating the development of heterotopic ossification. Further studies are necessary to determine the optimal time to institute EHDP treatment, length of treatment, and minimal effective dose. EHDP is the first therapeutic agent known to alter the formation of heterotopic ossification after spinal injury and may prove useful in other conditions where heterotopic ossification prevention is clinically indicated.

Acknowledgements. The disodium etidronate (EHDP) used in this investigation was supplied by Procter \& Gamble Company, Cincinnati, Ohio.

We are indebted to Ms Pamela Hornsby and Scott Michaels, Ph.D., for data compilation and statistical analysis.

This research project was supported in part by Grant No. I6-P-56807/4-9 from the Department of Health, Education and Welfare, Rehabilitation Services Administration.

\section{REFERE NCES}

Altman, R. D., Johnston, C. C., Khairi, M. R. A., Wellman, H. N., Serafini, A. N. \& SANKEY, R. R. (I973). Influence of disodium etidronate on clinical and laboratory manifestations of Paget's disease of bone (osteitis deformans). New Eng. F. Med. 289, I $379-$ I 384 .

Casey, P. A., Casey, G., Fleisch, H. \& Russell, R. G. G. (1972). The effect of polyphloretin phosphate, polyoestradiol phosphate, a diphosphonate and a polyphosphate on calcification induced by dihydrotachysterol in skin, aorta and kidney of rats. Experientia, 28, I37-I38. 
Fleisch, H. A., Russell, R. G. G., Bisaz, S., Mulhaubauer, R. C. \& Williams, D. A. (1970). The inhibitory effect of phosphonates on the formation of calcium phosphate crystals in vitro and on aortic and kidney calcification in vivo. Eur. F. Clinc. Invest. I, I $2-18$.

Francis, M. D., Flora, L. \& King, W. R. (I972). The effects of disodium ethane-1hydroxy-1, l-diphosphonate on adjuvant induced arthritis in rats. Calcif. Tissue Res. 9, 109.

Francis, M. D., Russell, R. G. G. \& Fleisch, H. (1969). Diphosphonates inhibit formation of calcium phosphate crystals in vitro and pathological calcification in vivo. Science, 165, I264-1266.

HaRdy, A. G. \& Dickson, J. W. (1963). Pathological ossification in traumatic paraplegia. F. Bone F. Surg. 45 B, $76-87$.

Khairi, M. R. A., Johnston, Jr., C. C., Altman, R. D., Wellman, H. N., Serafini, A. N.\& SANkeY, R. R. (I974). Treatment of Paget's disease of bone (osteitis deformans). F. Am. Med. Ass. 230, 562-567.

Michael, W. R., KING, W. R. \& WAKIM, J. M. (I972). Metabolism of disodium ethane-1hydroxy-1, l-diphosphonate (disodium etidronate) in the rat, rabbit, dog, and monkey. Toxic. appl. Pharmac. 21, 503-515.

Nicholas, J. J. (I973). Ectopic bone formation in patients with spinal cord injury. Arch. phys. Med. Rehabil. 54, 354-359.

Recker, R. R., Hassing, G. S., LAU, J. R. et al. (1973). The hyperphosphatemic effect of disodium ethane-1-hydroxy-1, 1-diphosphonate (EHDPTM): renal handling of phosphorus and the renal response to parathyroid hormone. f. Lab. Clin. Med. 8I, 258-266.

Rossier, A. B. (1975). Personal communication.

Rossier, A. B., Bussat, P., INFANTE, F. et al. (I973). Current facts on para-osteo-arthropathy (POA). Paraplegia, II, 36-78.

Russell, R. G. G., Kislig, A. M., Casey, P. A. \& Fleisch, H. (1973). The effect of diphosphonates and calcitonin on the chemistry and quantitative history of rat bone. Calc. Tissue Res. II, I79-195.

Russell, R. G. G., Smith, R., Preston, C., Walton, R. J. \& Woods, C. G. (1974). Diphosphonates in Paget's disease. Lancet, i, 894-898.

Stover, S. L., Hataway, C. J. \& Zeiger, H. E. (I975). Heterotopic ossification in spinal cord injured patients. Arch. phys. Med. Rehabil. 56, 199-204.

Stover, S. L., NiemanN, K. M. N. \& MilleR, III, J. M. (I975). Disodium etidronate in the prevention of postoperative recurrence of heterotopic ossification in spinal cord injury patients. To be submitted for publication.

VenieR, L. H. \& Ditunno, JR., J. F. (I97I). Heterotopic ossification in the paraplegic patient. Arch. phys. Med. Rehabil. 52, 475-479.

Wellman, H. N., Anger, R. T., Browne, A., Tofe, A., Francis, D., Khairi, R. \& JoHNSON, C. (I973). Evaluation of bone malignancy with 99m Tc-Sn-EHDP compared with $\mathrm{Na}^{18} \mathrm{~F}$. F. nucl. Med. 14, 464-465.

Wharton, G. W. \& MoRgan, T. H. (I970). Ankylosis in the paralyzed patient. F. Bone F. Surg. 52A, no. I, IO5-II2. 